\title{
MEASUREMENT OF THE DYNAMIC DISPLACEMENTS OF RAILWAY BRIDGES USING VIDEO TECHNOLOGY
}

\author{
Diogo Ribeiro ${ }^{1, a}$, Rui Calçada ${ }^{2}$, José Ferreira ${ }^{3}$ and Teresa Martins ${ }^{3}$ \\ ${ }^{1}$ Polytechnic of Porto, School of Engineering, Porto, Portugal \\ ${ }^{2}$ University of Porto, Faculty of Engineering, Porto, Portugal \\ ${ }^{3}$ Enermeter - Sistemas de Medição, Braga, Portugal
}

\begin{abstract}
This article describes the development of a non-contact dynamic displacement measurement system for railway bridges based on video technology. The system, consisting of a high speed video camera, an optical lens, lighting lamps and a precision target, can perform measurements with high precision for distances from the camera to the target up to $25 \mathrm{~m}$, with acquisition frame rates ranging from $64 \mathrm{fps}$ to $500 \mathrm{fps}$, and be articulated with other measurement systems, which promotes its integration in structural health monitoring systems. The system's performance was evaluated based on two tests, one in the laboratory and other on the field. The laboratory test evaluated the performance of the system in measuring the displacement of a steel beam, subjected to a point load applied dynamically, for distances from the camera to the target between $3 \mathrm{~m}$ and $15 \mathrm{~m}$. The field test allowed evaluating the system's performance in the dynamic measurement of the displacement of a point on the deck of a railway bridge, induced by passing trains at speeds between $160 \mathrm{~km} / \mathrm{h}$ and $180 \mathrm{~km} / \mathrm{h}$, for distances from the camera to the target up to $25 \mathrm{~m}$. The results of both tests show a very good agreement between the displacement measurement obtained with the video system and with a LVDT.
\end{abstract}

\section{Introduction}

The monitoring of the structural integrity of bridges is a current and relevant topic of research in structural engineering, motivated by the need of the owners and managers of infrastructures to reduce the costs of inspection and maintenance, while ensuring that the structural behaviour and the security level are appropriate throughout the bridge's useful life [1-4]. This monitoring is based on the continuous or periodical acquisition of an appropriate set of relevant measures of the structural response based on a network of transducers.

For railway bridges, one of the most relevant measures of the structural response is the dynamic displacement of the structure due to the passage of trains [5-6]. The displacement measurement systems can be classified as contact and non-contact measurement systems $[2-3,5]$.

The contact systems generally encompass high precision displacement transducers, such as LVDT, cable type, etc. The main disadvantage of these systems is their dependence on a reference because they are based on the relative displacement measurement between a point of the structure and a close point that can be considered fixed. This fixed point can, in many instances, be difficult, or even impossible, to materialize as, for example, when the structure is located over a watercourse, a road or in a rugged terrain, etc.
The non-contact measurement systems rely on laser technology [7], radar technology [8], GPS technology [9] and on the processing and analysis of images obtained by video technology $[3-4,6,10]$ or digital photography $[1$, $11]$.

The application of video technology based systems in the measurement of dynamic displacement of bridges due to high speed rail traffic is only briefly reported in the literature. The study carried out by Lee et al. [5] on the measurements of a railway bridge of the Korean high speed railway network was the only one identified.

Systems based on image processing have the advantage of establishing a good compromise between the acquisition frame rate and the resolution. These systems usually include a video camera, an optical lens, lighting lamps and a precision target fixed to the structure. Typical resolutions obtained in displacement measurements of bridges are within $0.1 \mathrm{~mm}$, for distances of $10 \mathrm{~m}$ between the video camera and target, and 1.0 $\mathrm{mm}$, for a distance of $100 \mathrm{~m}$ [9]. These systems have been used in static and quasi-static measurements for the performance of load tests on bridges [1-2, 4, 11-12]. More recently Bell et al. [1] and Malesa et al. [6] applied a technique, often referred as Digital Image Correlation (DIC), that doesn't require a target because is based on the tracking of a predefined pattern or texture of the structure.

\footnotetext{
${ }^{\mathrm{a}}$ Corresponding author: drr@isep.ipp.pt
} 
This article describes the development of a noncontact dynamic displacement measurement system based on video technology. The measurement system consists of a high speed video camera, an optical lens, lighting lamps and a precision target. The system has the following main advantages: versatility, as it can easily be articulated with other measuring systems, it can be programmed for acquisition frame rates from $64 \mathrm{fps}$ to $500 \mathrm{fps}$, and it can perform dynamic displacement measurements for distances from the camera to the target up to $25 \mathrm{~m}$ with high precision.

The system's performance was evaluated based on two tests, one in the laboratory and other on the field. The laboratory test evaluated the performance of the system in measuring the displacement of a steel beam, subjected to a point load applied dynamically, for distances from the camera to the target between $3 \mathrm{~m}$ and $15 \mathrm{~m}$. The field test allowed evaluating the system's performance in the dynamic measurement of the displacement of a point on the deck of a railway bridge, induced by passing trains at speeds between $160 \mathrm{~km} / \mathrm{h}$ and $180 \mathrm{~km} / \mathrm{h}$, for distances from the camera to the target up to $25 \mathrm{~m}$.

\section{Measurement system based on video technology}

\subsection{Architecture}

The measurement system based on video technology comprises the components presented in Figure 1.

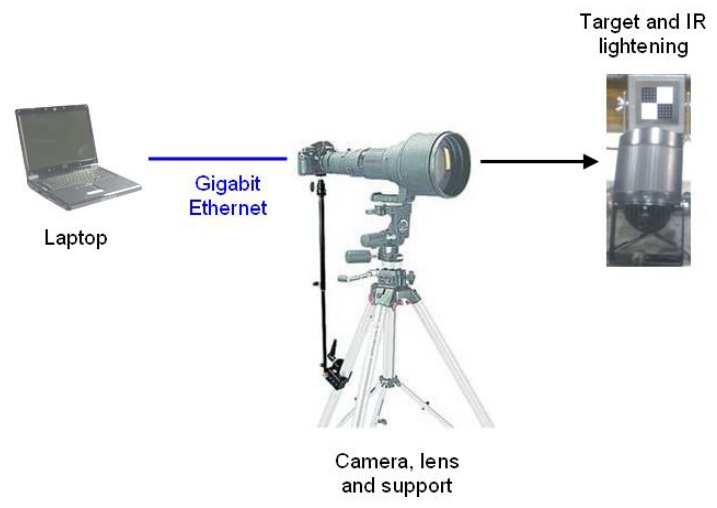

Figure 1. Measurement system based on video technology

Table 1 shows the characteristics of the different components of the system.

The main component of the system encompasses the high speed video camera, the lens and the magnification elements. The GENIE video camera, model H1400, has a maximum resolution of $1400 \times 1024$ pixels and an adjustable acquisition frame rate up to $500 \mathrm{fps}$. This camera presents the highest sensitivity in wavelengths between $600 \mathrm{~nm}$ and $700 \mathrm{~nm}$, located in the area of the near-infrared. It is equipped with a Nikon lens model 80400 VR F/4.5-5.6D ED. The magnification elements (duplicator and quadruplicator) enable to increase the depth of the field of view, and are useful in situations involving high distances between the video camera and the object.
Table 1. Technical characteristics of the systems' components.

\begin{tabular}{|c|c|c|}
\hline Component & $\begin{array}{l}\text { Brand / } \\
\text { Model }\end{array}$ & Technical characteristics \\
\hline $\begin{array}{l}\text { Laptop } \\
\text { computer }\end{array}$ & Clevo / D901C & $\begin{array}{l}\text { Operating system: Windows Pro } \\
\text { X64 } \\
\text { CPU: Intel Core } 2 \text { Quad } \\
\text { RAM: } 4 \text { Gb DDR3 } \\
\text { Discs: } 2 \times \text { SATA } 320 \mathrm{~Gb} \\
7200 \text { rpm } 16 \mathrm{Mb} \\
\text { Ethernet Board: Intel Pro } 1000\end{array}$ \\
\hline $\begin{array}{l}\text { Video } \\
\text { camera }\end{array}$ & & $\begin{array}{l}\text { Maximum resolution: } \\
1400 \times 1024 \\
\text { Frequency at maximum } \\
\text { resolution: } 64 \mathrm{fps} \\
\text { Pixel size: } 7.4 \mu \mathrm{m} \\
\text { Sensor: CMOS } \\
\text { Color: Monochrome } \\
\text { Output: Gigabit Ethernet } \\
\text { Lens mount: Type }+ \text { F-Mount } \\
\text { adaptator } \\
\text { Dimensions: } 44 \times 29 \times 67 \mathrm{~mm} \\
\text { Mass: } 115 \mathrm{~g} \\
\text { Sensitivity to visible and near IR } \\
(400 \text { a } 900 \mathrm{~nm})\end{array}$ \\
\hline Lens & $\begin{array}{l}\text { Nikon / } \\
\text { 80-400 VR } \\
\text { F4.5-5.6D ED }\end{array}$ & $\begin{array}{l}\text { Zoom: } 80 \text { to } 400 \mathrm{~mm} \\
\text { Luminosity: F } 4.5-5.6 \\
\text { Manual zoom and luminosity } \\
\text { control } \\
\text { Minimum focus distance: } 2.3 \mathrm{~m} \\
\text { Dimensions: } 91 \times 171 \mathrm{~mm}^{2} \\
\text { Weight: } 1.36 \mathrm{~kg}\end{array}$ \\
\hline \multirow{2}{*}{$\begin{array}{l}\text { Magnification } \\
\text { elements }\end{array}$} & Duplicator & $\begin{array}{l}\text { Magnification: } 2.0 x \text { extender } \\
\text { Mount: CS-Mount } \\
\text { Mounting threads: (2) M3 } \\
\text { Position: between lens and video } \\
\text { camera } \\
\text { Outer diameter: } 28 \mathrm{~mm} \\
\text { Length: } 12 \mathrm{~mm}\end{array}$ \\
\hline & Quadruplicator & $\begin{array}{l}\text { Magnification: } 4.0 x \text { extender } \\
\text { Mount: CS-Mount } \\
\text { Mounting threads: (2) M3 } \\
\text { Position: between lens and video } \\
\text { camera } \\
\text { Outer diameter: } 28 \mathrm{~mm} \\
\text { Length: } 33 \mathrm{~mm}\end{array}$ \\
\hline $\begin{array}{l}\text { Precision } \\
\text { target }\end{array}$ & & $\begin{array}{l}\text { Distance between reference } \\
\text { points: } 5( \pm 0.01) \mathrm{mm} \\
\text { Dimensions of the sticker: } \\
50 \times 50 \mathrm{~mm} \\
\text { Dimensions of the base: } \\
70 \times 70 \times 5 \mathrm{~mm} \\
\text { Material of the sticker: acrylic } \\
\text { Material of the base: stainless } \\
\text { steel }\end{array}$ \\
\hline $\begin{array}{l}\text { Tripod and } \\
\text { accessories }\end{array}$ & Manfrotto / & $\begin{array}{l}\text { Height minimum / maximum: } 44 \\
\text { / } 217 \mathrm{~cm} \\
\text { Weight: } 6,15 \mathrm{~kg} \\
\text { Maximum load: } 12 \mathrm{~kg} \\
\text { Bubble leveling } \\
\text { Accessories: rubber footings, } \\
\text { hydrostatic ball head and arm }\end{array}$ \\
\hline Lamps & $\begin{array}{c}\text { Derwent / } \\
\text { MF100 }\end{array}$ & $\begin{array}{l}\text { Infrared - Incandescent } \\
\text { Bulb life: average } 8000 \mathrm{~h} \\
\text { Aperture angles: } 10^{\circ}, 30^{\circ} \text { or } 60^{\circ} \\
\text { IR filters: } 730 \text { or } 830 \mathrm{~nm}\end{array}$ \\
\hline
\end{tabular}


The camera stand is composed of a tripod, a hydrostatic ball head and a support arm. The video camera is indirectly supported on the structure of the tripod with the assistance of an extensible support arm. The height of the tripod is generally limited to $1 \mathrm{~m}$, for stability reasons. The lens is attached to the tripod through a plate, which, in turn, is coupled to a hydrostatic ball head that enables small or large amplitude movements in all directions.

A laptop computer is used for storing and processing images. The images are directly stored in two hard drives running on RAID 0 system. The connection between the video camera and the laptop computer is performed by a Gigabit Ethernet interface that enables the data transference at a speed of approximately $1 \mathrm{~Gb} / \mathrm{s}$, for distances up to $100 \mathrm{~m}$, without resorting to repeaters.

In order to measure the displacement of a point on a given object, a precision target should be applied to that point. The precision target consists of an acrylic sticker glued to a metallic plate, consisting of four black and white squares ensuring a good contrast between the different coloured areas and also a good reflectivity to the infrared (IR). Each square has imprinted a grid of reference points with a regular spacing equal to $5 \mathrm{~mm}$ (tolerance of $\pm 0.01 \mathrm{~mm}$ ) used to scale and calculate the image resolution.

The illumination of the target is performed by IR incandescent lamps and generally it is necessary to use two of them, in order to minimize the influence of natural light.

The displacement measurement system based on video technology can easily be articulated with other measurement systems. Figure 2 shows the articulation with a National Instruments' cDAQ-9172 data acquisition system, used in the practical applications of this paper, later described in Sections 3 and 4.

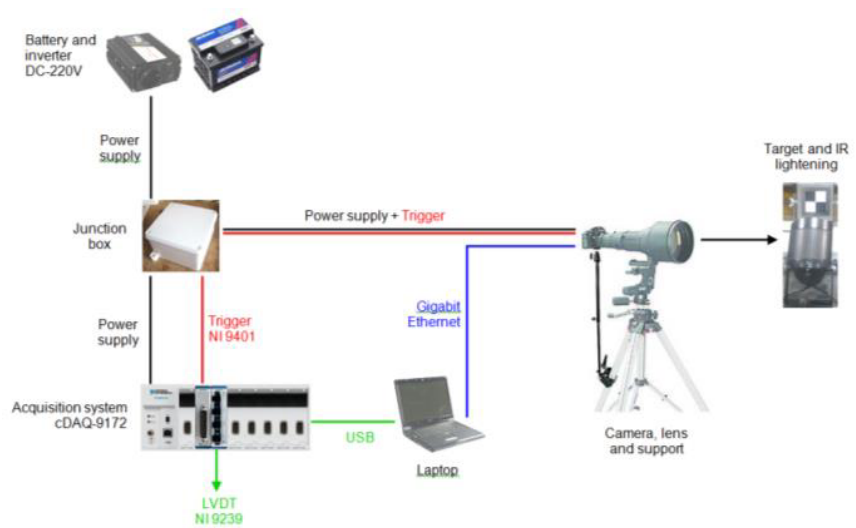

Figure 2. Articulation between the measurement system based on video technology and the National Instruments' cDAQ-9172 measurement system

The cDAQ-9172 measurement system allows the data acquisition from different sensors, namely LVDTs, accelerometers, strain gages, etc., through adequate analogue modules. The data synchronization is ensured through an analogue-digital module (NI 9401) by a trigger signal. The power supply of both systems is guaranteed by a set of batteries.

\subsection{Requirements and performance}

The system's basic requirement is to enable the performance of non-contact dynamic displacements measurements in distances to the objects up to $25 \mathrm{~m}$, with an acquisition frame rate up to $500 \mathrm{fps}$.

The theoretical resolution of an image $(R)$ can be calculated by the application of the following expression [13]:

$$
R=\frac{D_{s} d N}{n_{p x} f}
$$

where $D_{s}$ is the dimension of the camera's sensor, equal to $3.6 \mathrm{~mm}$ for the Genie camera that was used, $d$ is the distance from the camera to the object, $N$ is the Nyquist factor, equal to $2, n_{p x}$ is the number of active pixels of the camera on a given direction and $f$ represents the focal length.

Table 2 presents the number of active pixels of the video camera's sensor according to two directions ( 1 and 2) for various acquisition rates. These directions generally correspond to the vertical and horizontal directions, or vice versa, depending on the position of the camera in relation to the object. Scenario A considers the maximum number of active pixels in direction 1 while scenario $\mathrm{B}$ considers the maximum number of active pixels in both directions.

Table 2. Number of active pixels for various image acquisition rates.

\begin{tabular}{|c|c|c|c|c|}
\hline \multirow{2}{*}{$\begin{array}{c}\text { Acquisition rate } \\
\text { [fps] }\end{array}$} & \multicolumn{4}{|c|}{ Number of active pixels } \\
\cline { 2 - 5 } & \multicolumn{2}{|c|}{ Scenario A } & \multicolumn{2}{c|}{ Scenario B } \\
\cline { 2 - 5 } & Dir 1 & Dir 2 & Dir 1 & Dir 2 \\
\hline 64 & 1400 & 1024 & 1400 & 1024 \\
\hline 100 & 1400 & 658 & 960 & 960 \\
\hline 250 & 1400 & 260 & 880 & 413 \\
\hline 500 & 1400 & 131 & 880 & 203 \\
\hline
\end{tabular}

The increase of the image acquisition rate leads to a reduction in the number of active pixels of the camera. In scenario A, for the higher acquisition rates, such as 250 fps and $500 \mathrm{fps}$, the camera can provide the maximum number of active pixels in one direction while, in the other direction, the number of active pixels is significantly reduced. This feature is useful for the evaluation of displacements in a preferential direction. In scenario B, due to the architecture of the camera, above $250 \mathrm{fps}$ it is impossible to reduce the number of active pixels in direction 1 .

Figure 3 presents the values of the theoretical resolution of the image associated to direction 1 of the camera's sensor, according to the distance to the object for various focal lengths. The results consider the maximum number of active pixels of the camera's sensor and are valid for any value of the image acquisition rate. The focal length of the lens, equal to $400 \mathrm{~mm}$, can be increased to $800 \mathrm{~mm}$ or to $3200 \mathrm{~mm}$ by using a duplicator, or a duplicator associated with a quadruplicator, respectively. 


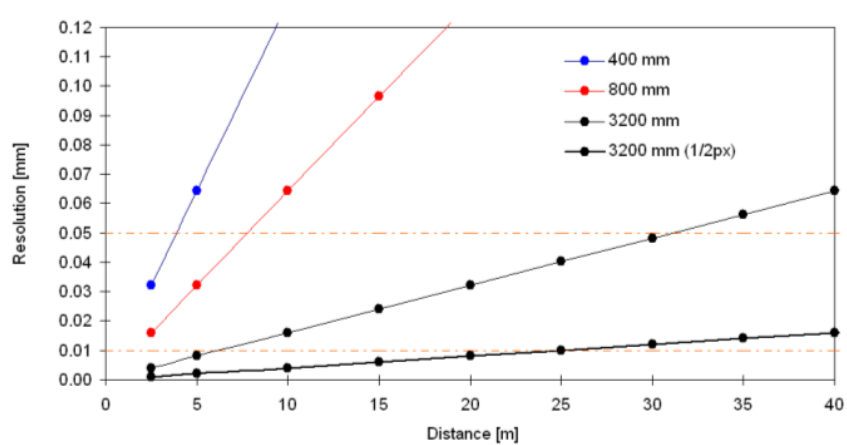

Figure 3. Theoretical resolution of the images according to the distance to the target and the focal length

For distances to the object in the order of $5 \mathrm{~m}$ it is possible to obtain an image resolution of approximately $0.01 \mathrm{~mm}$ by selecting a focal length of $3200 \mathrm{~mm}$. For distances in the order of $25 \mathrm{~m}$, to obtain a resolution of $0.01 \mathrm{~mm}$, it is necessary to use a focal length of $3200 \mathrm{~mm}$ and apply an image processing technique at subpixel level, in this case, at half pixel level [15]. Under these conditions the illumination of the target should be a critical aspect, since the use of the lens and magnification elements significantly reduces the light entrance into the camera's sensor.

\subsection{Software}

The image acquisition and processing software was developed based on the SAPERA [14] vision software and on a set of functions specifically developed for this work and compiled in $\mathrm{C}^{++}$environment. The graphical interface of the developed software, presented in Figure 4, includes several functionalities, namely, the definition of the regions of interest, the definition of the camera's parameters (acquisition frame rate, gain, shutter speed), the selection of the type of trigger, the monitoring of the image quality parameters (brightness and contrast) and the automatic processing of acquired images [15].

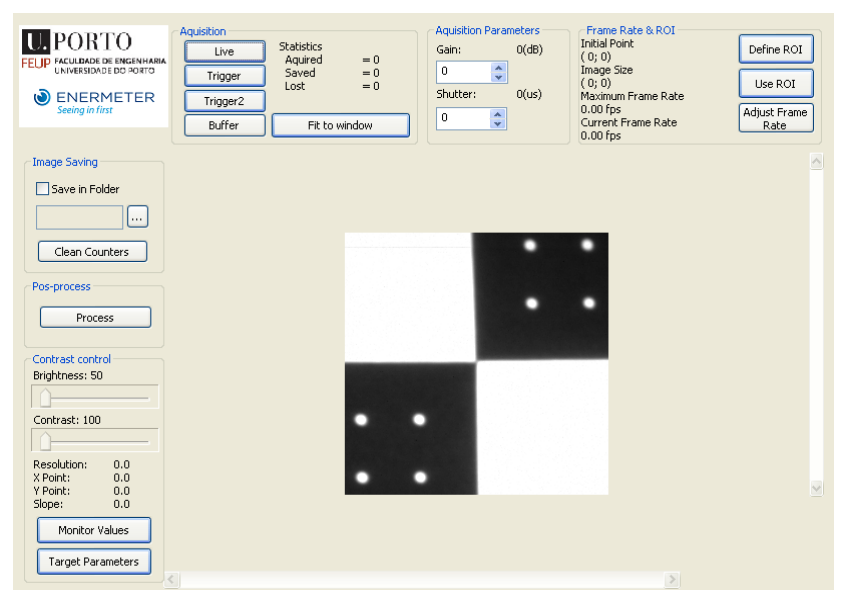

Figure 4. Graphical interface of the software for the acquisition and processing of images

The definition of a region of interest of a field of view is performed graphically by selecting a portion of the image using a rectangular window. This option enables to reduce the size of the images and, thereby, increase the acquisition frame rate, without altering the resolution of the images. The gain option enables to digitally increase the intensity of the gray levels of the image in situations where the field of view presents low luminosity. The trigger can be internally or externally activated [15]. The brightness and contrast are indicators of image quality monitored at the level of the region of interest. The optimal value of image brightness is equal to $50 \%$ while the optimal value of contrast is close to $100 \%$ [13].

\section{Laboratory test}

The laboratory test aims at evaluating the performance of the video technology based system through the confrontation of displacement measurements obtained with this system and with a conventional displacement sensor (LVDT).

\subsection{Description}

The laboratory test consisted in the measurement of the vertical displacement of a simply supported IPE100 metallic beam with a span of $0.90 \mathrm{~m}$, obtained by the application of a point load. The point load was applied dynamically to the midspan by means of a servo hydraulic actuator assembled on a reaction frame, according to the details presented in Figure 5 a).

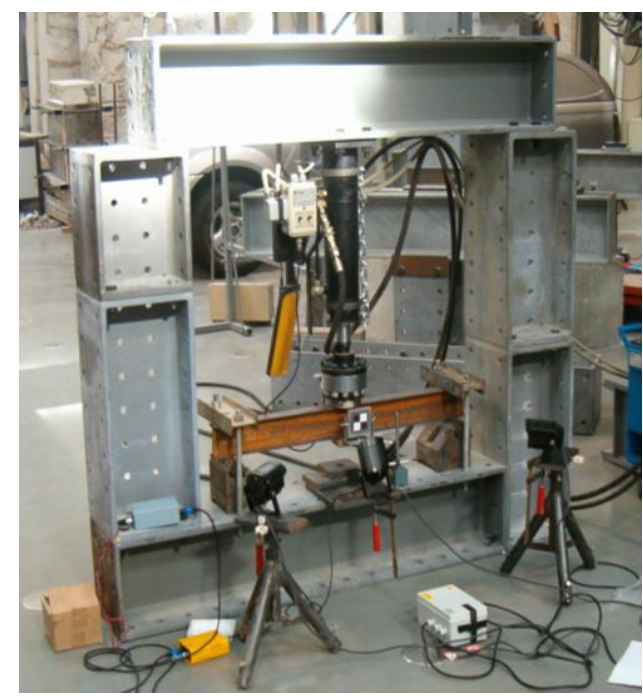

a)

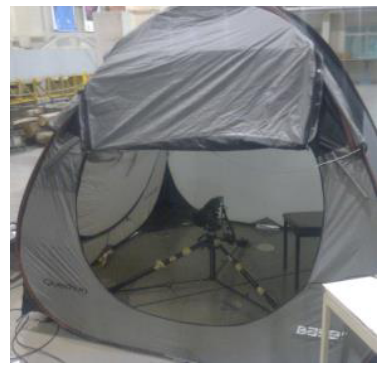

b)

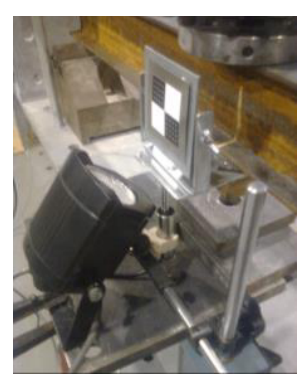

c)
Figure 5. Laboratory test: a) overview; b) camera's protection stall; c) target and lighting lamp

The camera was positioned at $3 \mathrm{~m}, 5 \mathrm{~m}, 10 \mathrm{~m}$ and $15 \mathrm{~m}$ from the target and placed inside a stall to minimize 
the movements of the stand that could be caused by the action of air flows (Figure $5 \mathrm{~b}$ )). The illumination was ensured by one or two IR incandescent lamps (Figure 5 a) and c)). The target was set on a metallic segment bonded to the lower flange of the beam as shown in Figure $5 \mathrm{c}$ ). The metallic segment enables the rotation of the target to ensure that its position is perpendicular to the camera. This operation was conducted with the assistance of a digital inclinometer. The LVDT was placed in the same section of the beam through a magnetic base attached to the reaction frame (Figure $5 \mathrm{c}$ )). The LVDT is a RDP, model DCTH100AG, with a measuring range equal to $\pm 2.5 \mathrm{~mm}$ and a precision in the order of $0.001 \mathrm{~mm}$.

The conditions of the measurements performed by the video system are summarized in Table 3. This table contains information about the distance to the target, the resolution of the images and the optical accessories used.

Table 3. Laboratory test: distance from the camera to the target, image resolution and optical accessories.

\begin{tabular}{|c|c|c|c|c|}
\hline \multirow{2}{*}{$\begin{array}{c}\text { Distance to } \\
\text { target }[\mathrm{m}]\end{array}$} & \multirow{2}{*}{$\begin{array}{c}\text { Resolution } \\
{[\mathrm{ppm}]}\end{array}$} & \multicolumn{3}{|c|}{ Optical accessories } \\
\cline { 3 - 5 } & & Lens & $2 \mathrm{x}$ & $4 \mathrm{x}$ \\
\hline 3 & 20.9 & $\times$ & & \\
\hline 5 & 24.4 & $\times$ & $\times$ & \\
\hline 10 & 22.4 & $\times$ & & $\times$ \\
\hline 15 & 14.7 & $\times$ & & $\times$ \\
\hline
\end{tabular}

The second IR incandescent lighting was used for the distances of $10 \mathrm{~m}$ and $15 \mathrm{~m}$, having a decisive role in the maintenance of the image quality in terms of brightness and contrast since, for these distances, the duplicator was replaced by the quadruplicator, which led to a significant brightness reduction in the field of view.

For distances of $3 \mathrm{~m}, 5 \mathrm{~m}$ and $10 \mathrm{~m}$ from the target the image resolution ranged from $20 \mathrm{ppm}$ to $25 \mathrm{ppm}$. For the distance of $15 \mathrm{~m}$ the images were acquired at a lower resolution and close to $15 \mathrm{ppm}$. This option was somewhat deliberate since the maintenance of the images' resolution would involve the combined use of the duplicator and the quadruplicator. However, the combined use of these magnification elements is not viable with the available means of lighting, since the reduction of light in the sensor of the camera is very significant.

\subsection{Results}

Figure 6 presents the results of the vertical displacement measurement at the midspan of the beam, by the video system and the LVDT, for distances from the camera to the target equal to $3 \mathrm{~m}, 5 \mathrm{~m}, 10 \mathrm{~m}$ and $15 \mathrm{~m}$.

The analysis of the graphs supports the conclusion that there is a good agreement between the displacement records measured by both systems, especially in the records obtained for distances of $3 \mathrm{~m}$ and $5 \mathrm{~m}$ from the camera to the target.

The absolute errors of the displacement measurement performed with the video system, taking as exact the measurement performed with the LVDT, are equal to

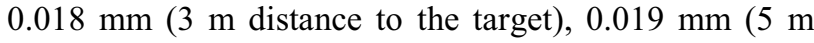
distance to the target), $0.031 \mathrm{~mm}$ (10 $\mathrm{m}$ distance to the target) and $0.042 \mathrm{~mm}$ (15 $\mathrm{m}$ distance to the target $)$. The

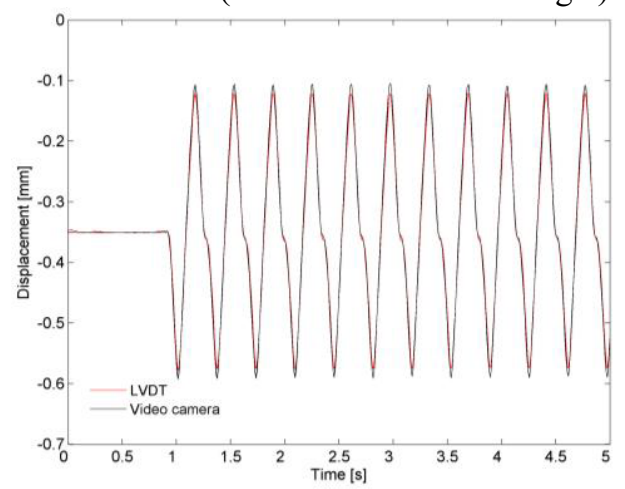

a)

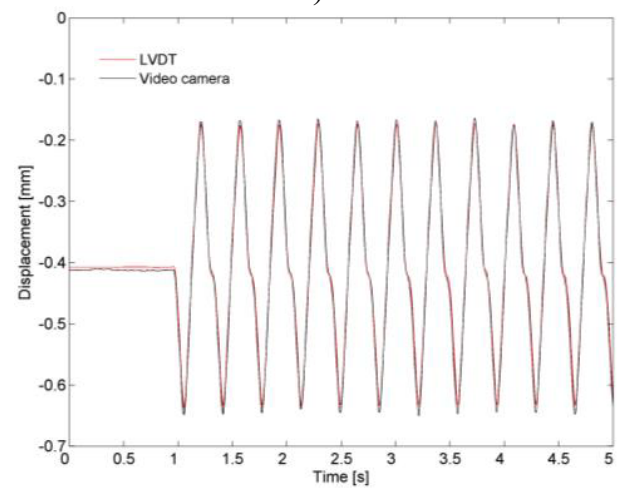

b)

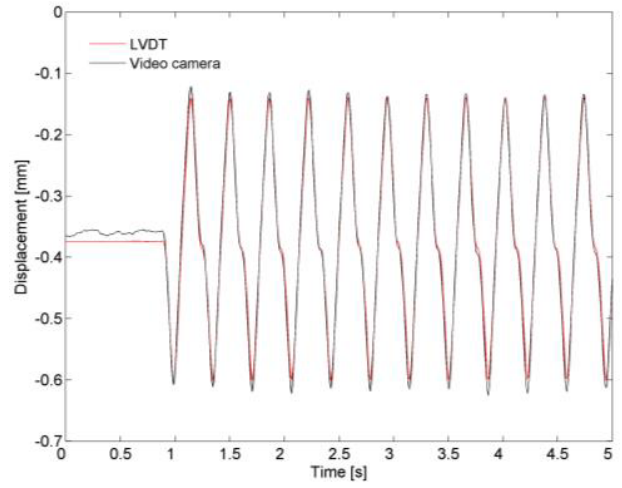

c)

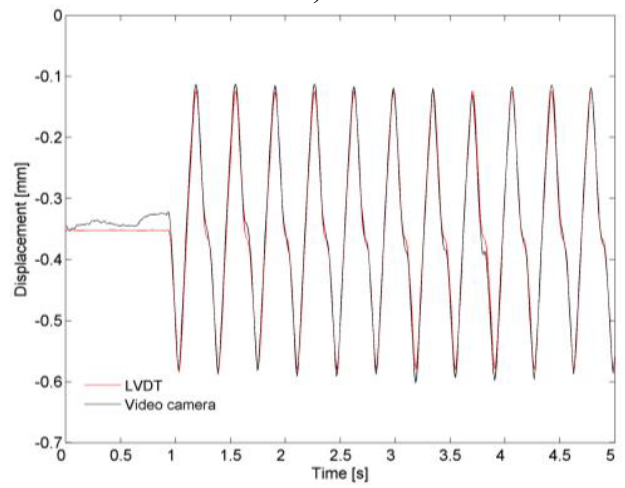

d)

Figure 6. Comparison of the vertical displacement of the beam measured with the video system and with the LVDT, for static and dynamic loadings, for camera to target distances of: a) $3 \mathrm{~m}$; b) $5 \mathrm{~m}$; c) $10 \mathrm{~m}$; d) $15 \mathrm{~m}$ 
errors were obtained based on the maximum difference registered between the displacements measured by the video system and by the LVDT. It is possible to conclude that the errors increase as the distance from the camera to the target increases.

Figure 7 compares the real and theoretical precision of the video measurement system. The theoretical precision $\left(p_{T}\right)$ is obtained by the application of the following expression:

$$
p_{T}=\frac{1}{R} N
$$

where $R$ is the resolution of the image expressed in pixels/mm and $N$ is the Nyquist factor associated to the camera's sensor CMOS, which is equal to 2 pixels.

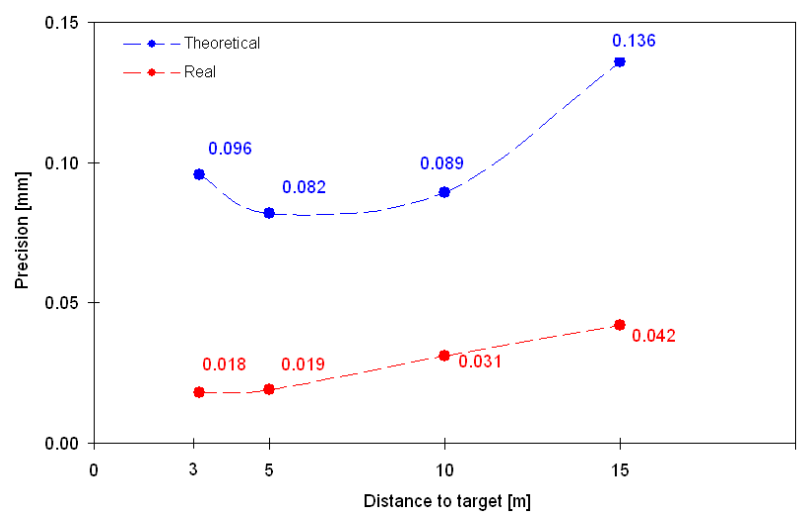

Figure 7. Comparison between the real and theoretical precisions in laboratory testing, according to the distance to the target

The analysis of the figure shows that the real precisions can be significantly higher than the theoretical precisions for all tested distances, demonstrating the efficiency of the image processing technique at subpixel level [15].

\section{Field test}

The field test involved the dynamic measurement of displacements of the São Lourenço bridge and aims evaluating the performance of the video system in an external environment. This bridge, located at the Northern line of the Portuguese railways', is a bowstring type bridge, consisting of two half decks with a $42 \mathrm{~m}$ span, formed by a prestressed concrete lower slab laterally suspended by metallic arches. The slab is suspended by means of metallic hangers and diagonals near the beginning of the arches [16]. Figure 8 presents a lateral view of the São Lourenço railway bridge.

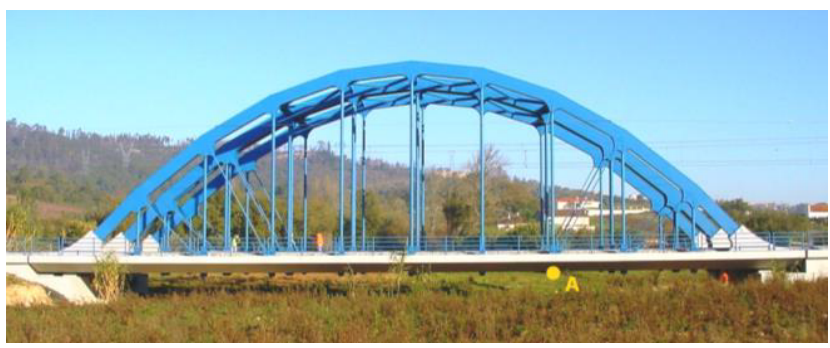

Figure 8. Lateral view of São Lourenço railway bridge with the identification of the measurement point

\subsection{Description}

The measurement of the vertical displacement of point $\mathrm{A}$ of the deck, identified in Figure 8, was performed for distances from the camera to the deck equal to $5 \mathrm{~m}$, $10 \mathrm{~m}, 15 \mathrm{~m}$ and $25 \mathrm{~m}$. The camera was installed in an adjacent terrain next to the bridge, inside a protective stall in order to reduce the influence of wind and possible air flow resulting from the passage of trains at high speed. The target was attached to a metallic plate of the hanger located at the lower level of the main beam.

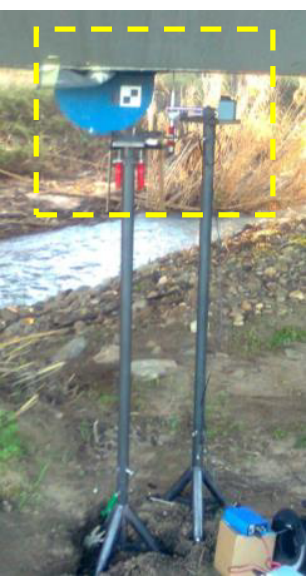

a)

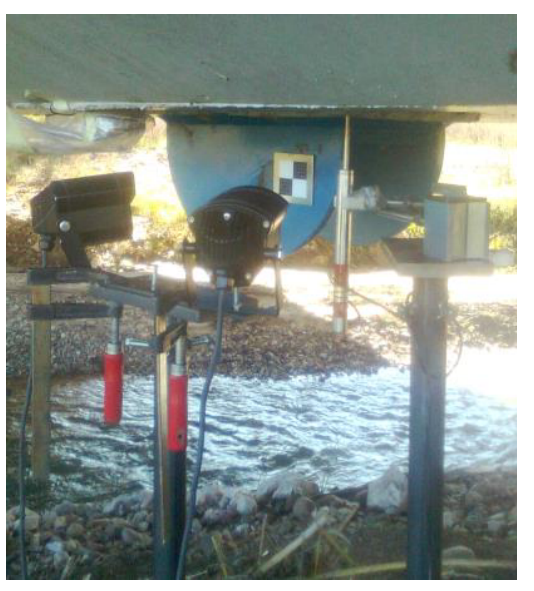

b)
Figure 9. Images of the LVDT and target placed on point A: a) overview and b) detail

The LVDT was positioned with the help of a magnetic base, which is supported by a metallic structure fixed to the ground. The LVDT is a RDP, model ACT1000A, with a measuring range equal to $\pm 25 \mathrm{~mm}$ and a precision in the order of $0.01 \mathrm{~mm}$. The lighting system, comprising two IR incandescent lamps supported by a metallic tripod, was installed at approximately 0.30 $\mathrm{m}$ from the target. The illumination lamps could also be supported by other type of accessories which do not require contact with the ground. The lamps were switched on just before the passing of the train to prevent overheating. Figure 9 illustrates an overview and a detail of the measurement site.

The measurement conditions of the video based system are summarized in Table 4, including the distance to the target, the image resolution and the optical accessories used.

Table 4. Test conditions with the video measurement system.

\begin{tabular}{|c|c|c|c|c|}
\hline \multirow{2}{*}{$\begin{array}{c}\text { Distance to the } \\
\text { target }[\mathrm{m}]\end{array}$} & \multirow{2}{*}{$\begin{array}{c}\text { Resolution } \\
{[\mathrm{ppm}]}\end{array}$} & \multicolumn{3}{|c|}{ Optical accessories } \\
\cline { 3 - 5 } & 21.0 & $\times$ & $\times$ & \\
\hline 5 & 12.5 & $\times$ & $\times$ & \\
\hline 10 & 14.5 & $\times$ & & $\times$ \\
\hline 15 & 20.0 & $\times$ & $\times$ & $\times$ \\
\hline 25 & & & & \\
\hline
\end{tabular}

It is possible to conclude that the resolution of the system ranged between $12.5 \mathrm{ppm}$ and $21 \mathrm{ppm}$ in all measurements. The existing natural light in the field 
allowed the camera's sensor to have an available amount of light superior to that of the laboratory test. However, the luminosity showed significant variability during measurement due to the alteration of weather conditions. This fact led to the necessity of introducing a digital gain in the images in order to stabilize the values of the brightness and contrast parameters.

\subsection{Results}

Figure 10 shows the vertical displacement records from point A of the deck, obtained through the LVDT and through the video system, with the camera located at $5 \mathrm{~m}$, $10 \mathrm{~m}, 15 \mathrm{~m}$ and $25 \mathrm{~m}$ from the target, for the passage alfa pendular trains, at speeds near $180 \mathrm{~km} / \mathrm{h}$, and intercity trains at speeds near $160 \mathrm{~km} / \mathrm{h}$. The load schemes of these trains are presented in [15].

The observation of the graphs demonstrates that, for all considered distances, there is a very good agreement between the displacement records measured with the video system and with the LVDT.

The absolute errors of displacement measurements performed with the video system, taking as exact the measurements performed with the LVDT, are equal to $0.067 \mathrm{~mm}$ (5 m distance to the target), $0.103 \mathrm{~mm}(10 \mathrm{~m}$ distance to the target), $0.107 \mathrm{~mm}$ (15 $\mathrm{m}$ distance to the target) and $0.274 \mathrm{~mm}$ (25 $\mathrm{m}$ distance to the target). The errors refer to the largest registered difference between the displacement measured by the video system and by the LVDT. Just as in the laboratory test there is a tendency for error increase as the distance to the target increases.

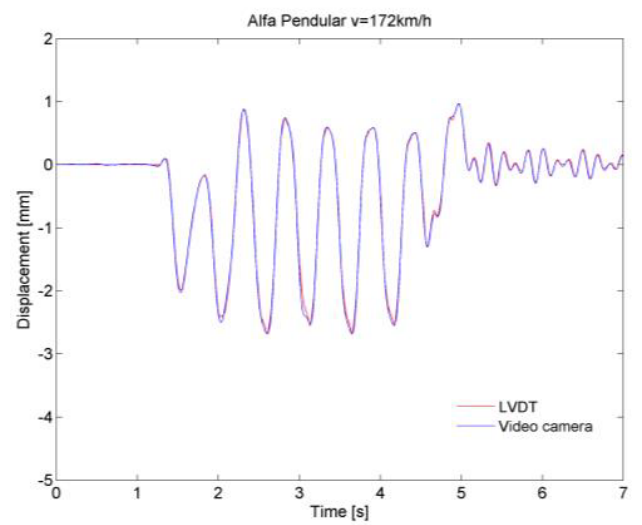

a)

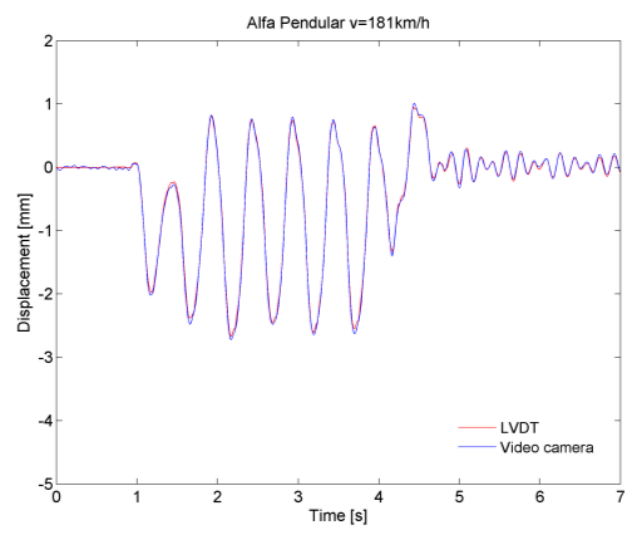

b)

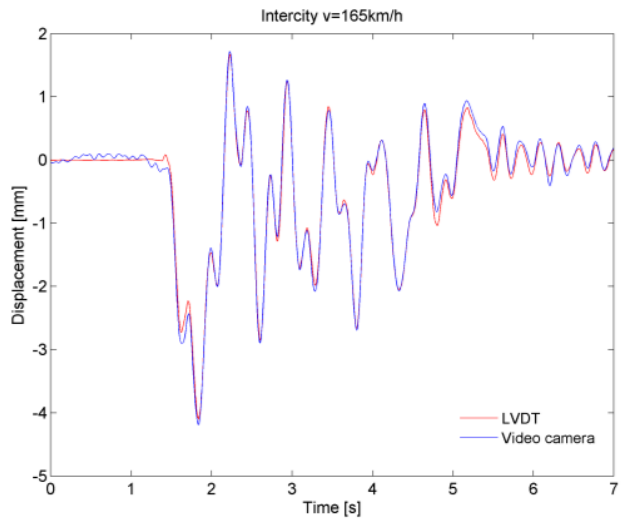

c)

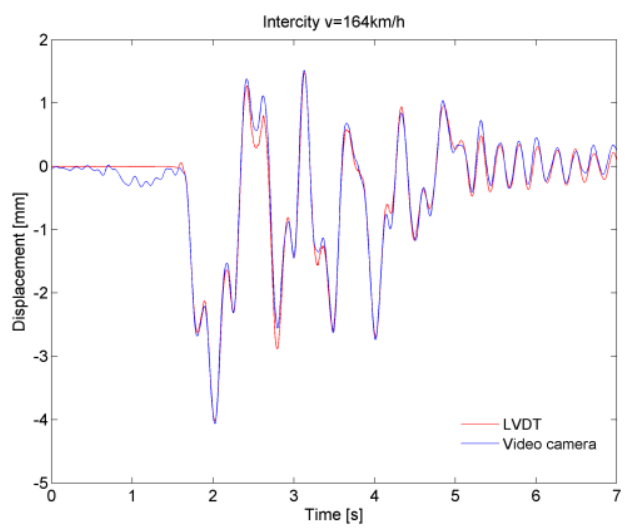

d)

Figure 10. Comparison of the measurements of vertical displacement of the deck with the video system and with the LVDT, for the passage of alfa pendular and intercity trains, for camera to target distances of: a) $5 \mathrm{~m}$; b) $10 \mathrm{~m}$;) $15 \mathrm{~m}$; d) $25 \mathrm{~m}$

Figure 11 presents a comparison of the real and theoretical precisions of the video measurement system.

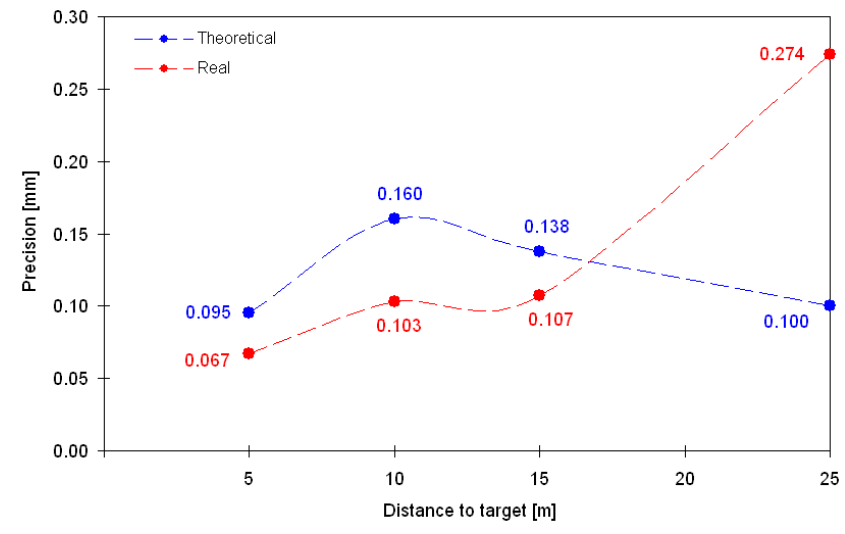

Figure 11. Theoretical and real precision of the measurements performed in the field according to the distance from the camera to the target

The analysis of the figure shows that the real precision values are lower than the theoretical precision values, except for the distance of $25 \mathrm{~m}$. It should also be noted that the precision gain resulting from the application of the image processing technique at subpixel level was significantly lower than that observed in the laboratory test. The reasons for this reduction are 
possibly related to the fact that the values of the brightness and contrast parameters are not equal to the optimal values, and to the existence of noise in the images due to the inclusion of digital gain.

The unusual behaviour of the images' resolution for the distance of $25 \mathrm{~m}$ can be justified by the inclusion of a very high value of digital gain, which aimed to compensate for the reduced light input into the camera's sensor, due to the combined use of the duplicator and quadruplicator.

\section{Conclusions}

This article describes the development of a non-contact dynamic displacement measurement system for railway bridges based on video technology and its application in laboratory and field testing.

The laboratory test of a beam subjected to static and dynamic loading resulted in a good agreement between the measurements obtained with the video system and with the LVDT. The obtained precision was below $0.05 \mathrm{~mm}$ for distances from the camera to the target up to $15 \mathrm{~m}$.

The field test of the São Lourenço railway bridge presented a good agreement between the displacement measurements obtained with the video system and with the LVDT, for the passage of trains at speeds between $160 \mathrm{~km} / \mathrm{h}$ and $180 \mathrm{~km} / \mathrm{h}$. The obtained precision was below $0.1 \mathrm{~mm}$ for distances from the camera to the target up to $15 \mathrm{~m}$, and in the order of $0.25 \mathrm{~mm}$ for a distance of $25 \mathrm{~m}$.

In future works, the authors intend to introduce improvements in the measurement system based on video technology, in order to: i) apply it to distances from the structure to the camera of over $25 \mathrm{~m}$, which may involve the use of a wide-ranging telescopic lens; ii) allow the simultaneous displacement measurement of various points of the structure, developing the software in order to process multiple regions of interest in the images associated with several targets, and iii) discard the placement of targets in the structure, through the implementation and application of DIC techniques.

\section{Acknowledgments}

The present work has been funded by the Portuguese Foundation for Science and Technology (FCT), in the context of Research Project FCOMP-01-0124-FEDER007195. The authors also would like to thank REFER, the company responsible for the management of the Portuguese railway network, for the support on the realization of the field tests, and to Eng. Henry Simões, from Infaimon, for the cooperation and information provided about the video camera, lens and lighting system.

\section{References}

1. Bell E, Peddle J, Goudreau A. Bridge condition assessment using digital image correlation and structural modeling. IABMAS'12 - Bridge Maintenance, safety, management, resilience and sustainability. Dubrovnik, Croatia.2012. p. 330-7.

2. Lee J, Cho S, Shinozuka M, Yun C, Lee C, Lee W. Evaluation of bridge load carrying capacity based on dynamic displacement measurement using real-time image processing techniques. Steel Structures. 2006;6:377-85.

3. Lee J, Fukuda Y, Shinozuka M, Cho S, Yun C. Development and application of a vision-based displacement measurement system for structural health monitoring of civil structures. Smart Structures and Systems. 2007;3:373-84.

4. Lee J, Shinozuka M. A vision-based system for remote sensing of bridge displacement. NDT\&E International. 2006;39:425-31.

5. Lee J, Oh J, Park M, Kwon S, Kwark J. Bridge displacement measurement system using image processing. IABMAS'06 - Bridge Maintenance, safety, management, resilience and sustainability. Porto, Portugal. 2006.

6. Malesa M, Szczepanek D, Kujawinska M, Swiercz A, Kolakowski P. Monitoring of civil engineering structures using digital image correlation technique. ICEM 14 - 14th International Conference on Experimental Mechanics. Poitiers, France. 2010.

7. Nassif H, Gindy M, Davis J. Comparison of laser Doppler vibrometer with contact sensors for monitoring bridge deflection and vibration. NDT\&E International. 2005;38:213-8.

8. Gentile C, Bernardini G. An interferometric radar for non-contact measurement of deflections on civil engineering structures: laboratory and full-scale tests. Structure and Infrastructure Engineering. 2010;6:52134.

9. Stephen G, Brownjohn J, Taylor C. Visual monitoring of the Humber bridge. Engineering Structures. 1993; 15:197-208.

10. Chang C, Ji Y. Flexible videogrammetric technique for three-dimensional structural vibration measurement. Journal of Engineering Mechanics. 2007;133:656-64.

11. Jáuregui D, White K, Woodward C, Leitch K. Noncontact photogrammetric measurement of vertical bridge deflection. Journal of Bridge Engineering. 2003;8:212-22.

12. Kim S, Kim N. Multi-point displacement response measurement of civil infrastructures using digital image processing. Procedia Engineering. 2011;14:195-203.

13. Forsyth D, Ponce J. Computer vision: a modern approach. 2nd ed: Prentice Hall; 2011.

14. Sapera. Sapera++ LT ${ }^{\text {TM }} 6.20$ - Programmer's Manual. St-Laurent, Quebec: DALSA Corporation; 2006.

15. Ribeiro D, Calçada R, Ferreira J, Martins T. Noncontact measurement of railway bridges dynamic displacement using an advanced video-based system. Engineering Structures. 2014;75:164-80.

16. Ribeiro D, Calçada R, Delgado R, Brehm M, Zabel V. Finite element model updating of a bowstring-arch railway bridge based on experimental modal parameters. Engineering Structures. 2012;40:413-35. 